\title{
Innervation of the pineal gland in the Arctic fox (Vulpes lagopus) by nerve fibres immunoreactive to substance $P$ and calcitonin gene-related peptide
}

\author{
M. Bulc ${ }^{1}$, B. Lewczuk ${ }^{2}$ \\ ${ }^{1}$ Department of Clinical Physiology, Faculty of Veterinary Medicine, University of Warmia and Mazury in Olsztyn, Poland \\ ${ }^{2}$ Department of Histology and Embryology, Faculty of Veterinary Medicine, University of Warmia and Mazury in Olsztyn, \\ Poland
}

[Received: 6 December 2018; Accepted: 29 January 2019]

\begin{abstract}
Background: The study demonstrates, for the first time, the presence of substance $P$ $(S P)$ and calcitonin gene-related peptide (CGRP) in the nerve fibres supplying the pineal gland in the Arctic fox.

Materials and methods: The expression and distribution pattern of the studied substances were examined by double-labelling immunofluorescence technique. Results: The SP-positive fibres enter into the pineal gland through the capsule as the nervi conarii. The fibres formed thick bundles in the capsule and connective tissue septa, from where they penetrated into the pineal parenchyma. Inside the parenchyma, the nerve fibres created basket-like structures surrounding clusters of pinealocytes. The density of intrapineal SP positive fibres was slightly higher in the distal and middle parts of the gland than in the proximal one. Double immunostaining with antibodies against $S P$ and CGRP revealed that the vast majority of SP positive fibres were also CGRP positive. The fibres showing a positive reaction to $S P$ and negative to CGRP were scattered within the whole gland. The fibres immunopositive to CGRP and immunonegative to SP were not observed. In the habenular and posterior commissural areas adjoining to the pineal gland the immunoreactive nerve fibres were not found. Moreover, no immunopositive cell bodies were observed in both the pineal gland and the commissural areas.

Conclusions: These results reveal that SP and CGRP are involved in the innervation of pineal gland in carnivores. In turn we suggest that these peptides can regulate/ Imodulate melatonin secretion. (Folia Morphol 2019; 78, 4: 695-702)
\end{abstract}

Key words: pineal gland, nerve fibres, substance $P$, calcitonin gene-related peptide, immunohistochemistry, Arctic fox

\section{INTRODUCTION}

The pineal gland is an endocrine organ involved, due to the rhythmic secretion of melatonin, in regulation of many phenomena occurring in daily and seasonal cycles [38]. In mammals, this rhythmical secretory activity is generated by the suprachiasmatic nucleus of the hypothalamus, which receives informa- tion about the environmental light conditions from the retina. The neuronal signals from suprachiasmatic nucleus are transmitted via the multisynaptic pathway to the pineal gland. The last element of this pathway comprises the sympathetic nerve fibres, which perikarya are located in the superior cervical ganglia $[21,40]$. Noradrenaline is rhythmically released from

Address for correspondence: Dr. M. Bulc, Department of Clinical Physiology, Faculty of Veterinary Medicine, University of Warmia and Mazury in Olsztyn, ul. Oczapowskiego 13,10-719 Olsztyn, Poland, e-mail: michal.bulc@uwm.edu.pl 
these fibres and induces the nocturnal increase in melatonin synthesis and secretion [38]. In addition to the sympathetic innervation, the mammalian pineal organ contains a large number of nerve fibres expressing numerous biologically active peptides that originate from the brain and various peripheral ganglia $[13,20,24,25,28-31,37]$. Among them, there are nerve fibres containing substance $P(S P)$ and calcitonin gene-related peptide (CGRP).

Substance $P$ is an undecapeptide and belongs to the tachykinin/neurokinin family. This family comprises, in addition to SP, neurokinin A (NKA) and neurokinin $B$ (NKB) [6]. The tachykinins are encoded by two different genes. Thus, SP and NKA are encoded by the preprotachykinin I gene, while NKB is encoded by the preprotachykinin II gene [8]. SP is considered to be the neurotransmitter for primary sensory afferent nerve fibres, where is involved in nociception. Another functions performed by SP include involvement in the regulation of pituitary hormone release, cardiovascular control and baroreceptor reflex $[7,26]$. The immunohistochemical studies performed on few species demonstrated considerable differences between mammals in the density and distribution of SP-positive fibres in the pineal gland [10, 12, 18, 25, $28,33,37]$. The putative sources of the intrapineal SP-positive fibres are the medial habenular nucleus and the trigeminal ganglion [32]. The data on function of SP in the mammalian pineal gland are enigmatic [22].

Calcitonin gene related peptide is a member of the calcitonin family of peptides [35]. CGRP is one of the most abundant peptides produced in the peripheral and central nervous systems $[2,5,9]$. This peptide is synthesized in the cell bodies of motor neurons in the anterior horn of the spinal cord and may contribute to the regeneration of nervous tissue after injury. Together with SP, CGRP may be linked to the transmission of pain in the posterior horn of the spinal cord $[2,4]$. In the pineal gland, expression of CGRP was exclusively described in rodents, the tree shrew and the pig $[10,12,25,31,37]$. In the latter case, a significant degree of co-localisation between CGRP and SP was reported [25]. A role of these peptides in the pineal gland is completely unknown.

Except the histology and ultrastructure, which have been studied in the dog, cat, fox and mink $[1,3,4,41]$ the knowledge about the carnivore pineal gland is fragmentary and largely limited. As concerning innervation, the available data describe only the sympathetic [15] and vasopressinergic inputs [14] in the dog pineal gland as well as the neuropeptide $Y$-immunoreactive fibres in the cat and mink pineal glands $[17,19]$. The experimental studies showed that melatonin plays an important role in the control of the breeding season and the mounting cycle in foxes $[16,23,39]$. Melatonin has also positive effect on mink coat [34]. In view of the data concerning significance of melatonin in the carnivore physiology, further studies on the pineal gland in this group of mammals are highly desirable.

The aim of present study was to investigate by double immunohistochemistry the presence and distribution of structures containing SP and CGRP in the pineal gland of the Arctic fox. This species was chosen as a study object because of two reasons:

- the Arctic fox should be considered as a model for research on the pineal gland physiology in accompanying carnivores, as the studies on dogs and cats are significantly limited due to ethical reasons and legal regulations;

- the pineal gland and melatonin play an essential role in the seasonal changes in fox physiology and the knowledge about these phenomena is important due to practical reasons.

\section{MATERIALS AND METHODS}

\section{Animals and material collection}

Adult Arctic foxes $(n=8)$, aged 3-4 years, housed in natural light conditions in outdoor cages in a farm near Olsztyn (Poland) were used. They were fed in accordance to the nutritional regime for foxes and had free access to water. The animals were killed in Winter, according to the approved procedure for fur animal farms. The pineal glands were removed immediately after skinning and prepared for immunohistochemical examinations.

\section{Immunohistochemical studies}

The pineal glands were fixed in $4 \%$ paraformaldehyde in $0.1 \mathrm{M}$ phosphate buffer saline (PBS), $\mathrm{pH}=7.4$ for $60 \mathrm{~min}$, rinsed several times with PBS, transferred into $30 \%$ sucrose solution and stored at $4{ }^{\circ} \mathrm{C}$ until sectioning. The tissue blocks were cut in the frontal or sagittal planes using Microm HM 560 cryostat (Carl Zeiss, Germany) at a thickness of $12 \mu \mathrm{m}$ and mounted on gelatinised glass slides. The sections were processed for a double-immunofluorescence staining followed by DAPI nuclear staining. Shortly, after drying at $32^{\circ} \mathrm{C}$ for $45 \mathrm{~min}$, the sections were rinsed 
Table 1. List of primary and secondary antisera used in the study

\begin{tabular}{lcccc}
\hline Antigen & Species of origin & Code & Dilution & Supplier/Country \\
\hline Primary antisera & Rat & $8450-0505$ & & AbD Serorec/USA \\
$\begin{array}{l}\text { Substance P } \\
\text { Calcitonin gene-related peptide }\end{array}$ & Rabbit & $A B 5920$ & $1: 100$ & Chemicon/USA \\
$\begin{array}{l}\text { Secondary antisera } \\
\text { Alexa Fluor 488 }\end{array}$ & & & & \\
Alexa Fluor 546 & Donkey anti-rat & A11081 & $1: 1000$ & Molecular Probes/USA \\
\hline
\end{tabular}

in PBS $(3 \times 10 \mathrm{~min})$ and incubated in $10 \%$ horse serum in PBS with $0.3 \%$ Triton $X-100$ and $1 \%$ bovine serum albumin (BSA) for $20 \mathrm{~min}$. Then, the sections were incubated overnight at $4{ }^{\circ} \mathrm{C}$ with primary antibodies (listed in Table 1) diluted in PBS containing $0.3 \%$ Triton $\mathrm{X}-100$ and $1 \%$ BSA. On the following day, the sections were rinsed in PBS $(3 \times 5 \mathrm{~min})$ and incubated with secondary antibodies (Table 1) at a concentration $7.5 \mu \mathrm{g} / \mathrm{mL}$ (in PBS containing $0.25 \%$ BSA and $0.1 \%$ Triton $\mathrm{X}-100)$ for $4 \mathrm{~h}$. Then, the sections were again rinsed in PBS $(3 \times 5 \mathrm{~min})$, incubated for $10 \mathrm{~min}$ in a $500 \mathrm{nM}$ solution of DAPI (Invitrogen, USA), rinsed in PBS $(3 \times 5 \mathrm{~min})$ and cover slipped with polyethylene glycol/glycerin solution. The prepared specimens were viewed and photographed using an Axioimager microscope Z1 equipped with an Apotome and an AxioCam HRm digital camera (Carl Zeiss, Germany). We analysed all sections per animals, whereas to prevent photographed the same nerve fibres the pictures were made from every fifth sections. Negative controls used in the immunofluorescence procedure included pre-absorption of antisera with appropriate neuropeptides (100 $\mu \mathrm{g}$ of appropriate antigen per $1 \mathrm{~mL}$ of corresponding antibody at working dilution), omission of the primary antisera and replacement of the primary antisera with non-immune sera.

\section{RESULTS}

The SP-immmunoreactive (SP-IR) nerve fibres entered into to the pineal gland as the nervi conarii (Fig. 1A). They formed thick bundles in the capsule and just beneath it (Fig. 1B). The nerve fibres penetrated from the capsule to the connective tissue septa (Fig. 1C, D) and later to the parenchyma, where they created a dense network (Fig. 1E). Inside the parenchyma, the fibres formed basket - like structures surrounding clusters of pinealocytes (Fig. 1F). The density of SP-IR fibres was slightly higher in the distal and middle parts of the pineal gland than in the proximal one (Fig. 2).

Double immunostaining (Fig. 3A-F) against SP and CGRP demonstrated that the vast majority of SP-positive fibres were also CGRP-immmunoreactive (CGRP-IR). The fibres showing a positive reaction to SP and negative to CGRP were present within the whole gland. The fibres immunopositive to CGRP and immunonegative to SP were not found.

In the habenular and posterior commissural areas adjoining to the pineal gland, the fibres under interest were not present (Fig. 2). Moreover, no immunopositive cell bodies were observed in both the pineal gland and the commissural areas.

\section{DISCUSSION}

To the best of our knowledge, this paper describes for the first time the presence and distribution of SPand CGRP-immunopositive nerve fibres in the carnivore pineal gland. Up till now, SP has been detected in the nerve terminals supplying the pineal gland in rodents, the rat [13], cotton rat [12], gerbil [37], Chinese hamster [13], tupaiidae, the tree shrew [10], ungulates, the bovine [18], pig [25, 29] and primates, the macaque [33] as well as in the human [27]. A list of species, where the presence and distribution of CGRP-IR structures have been investigated in the pineal gland is much shorter and includes the gerbil [37], rat [13], cotton rat [12], tree shrew [10] and pig [29].

Interestingly, our data showed that the fox pineal gland possesses an exceptionally rich innervation by SP-containing fibres comparing to many other investigated species. The density of positive nerve fibres was apparently higher in the fox than in rodents and ungulates $[13,25,28]$ and similar to that in the macaque [33].

The obtained results demonstrated some region-dependent differences in the distribution of 

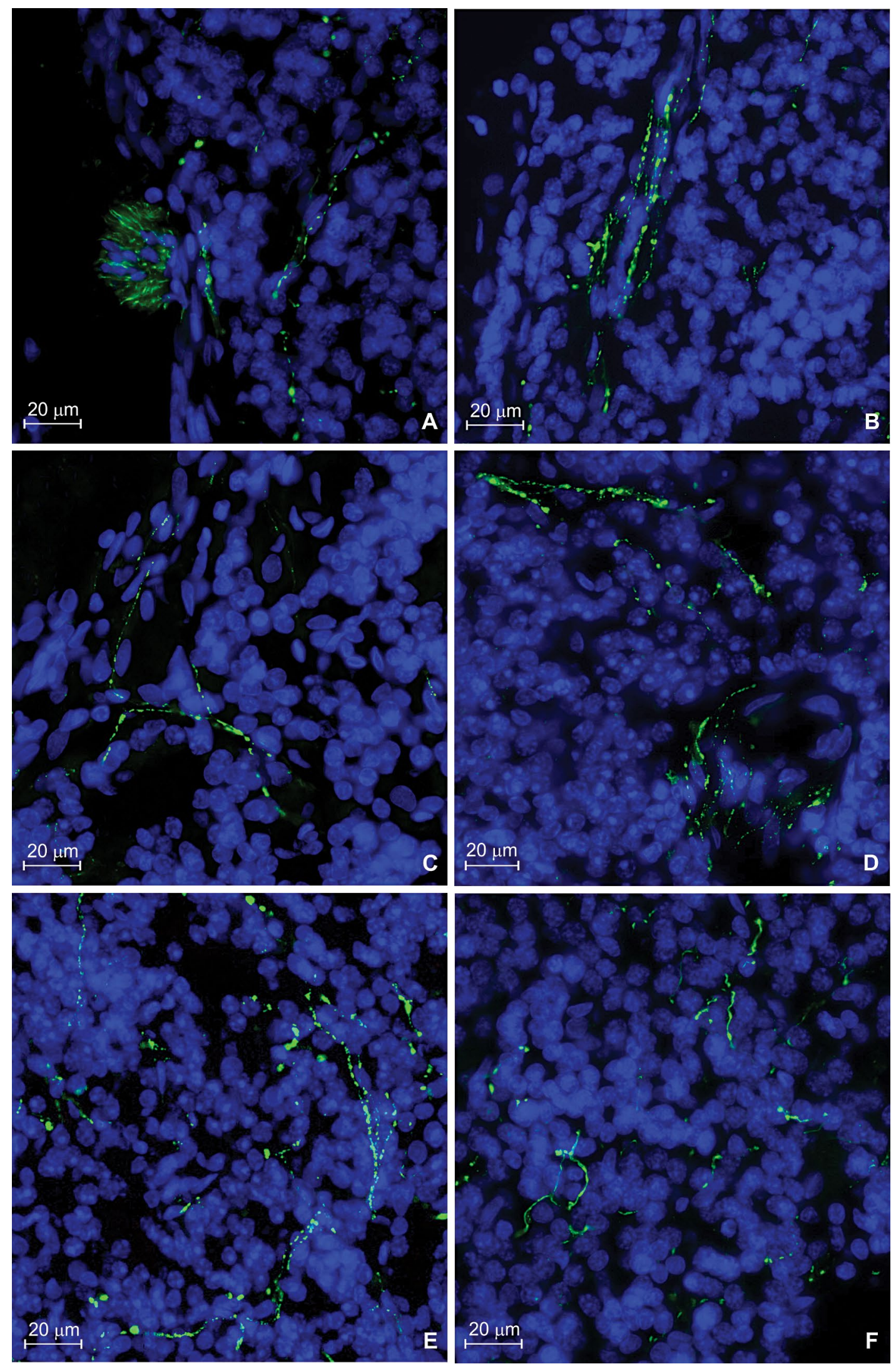

Figure 1. Localisation of substance P-immmunoreactive (SP-IR) nerve fibres in the fox pineal gland; $\mathbf{A}$. Immunopositive nerve fibres entering into the pineal gland as nervi conarii; $\mathbf{B}$. Thick bundles of positive fibres beneath the capsule; C. Immunopositive fibres penetrating from the capsule to the connective tissue septa; D. Positive nerve fibres in the connective tissue septa and parenchyma; E. A dense network of positive nerve fibres inside parenchyma; F. Positive nerve fibres between pinealocytes. 


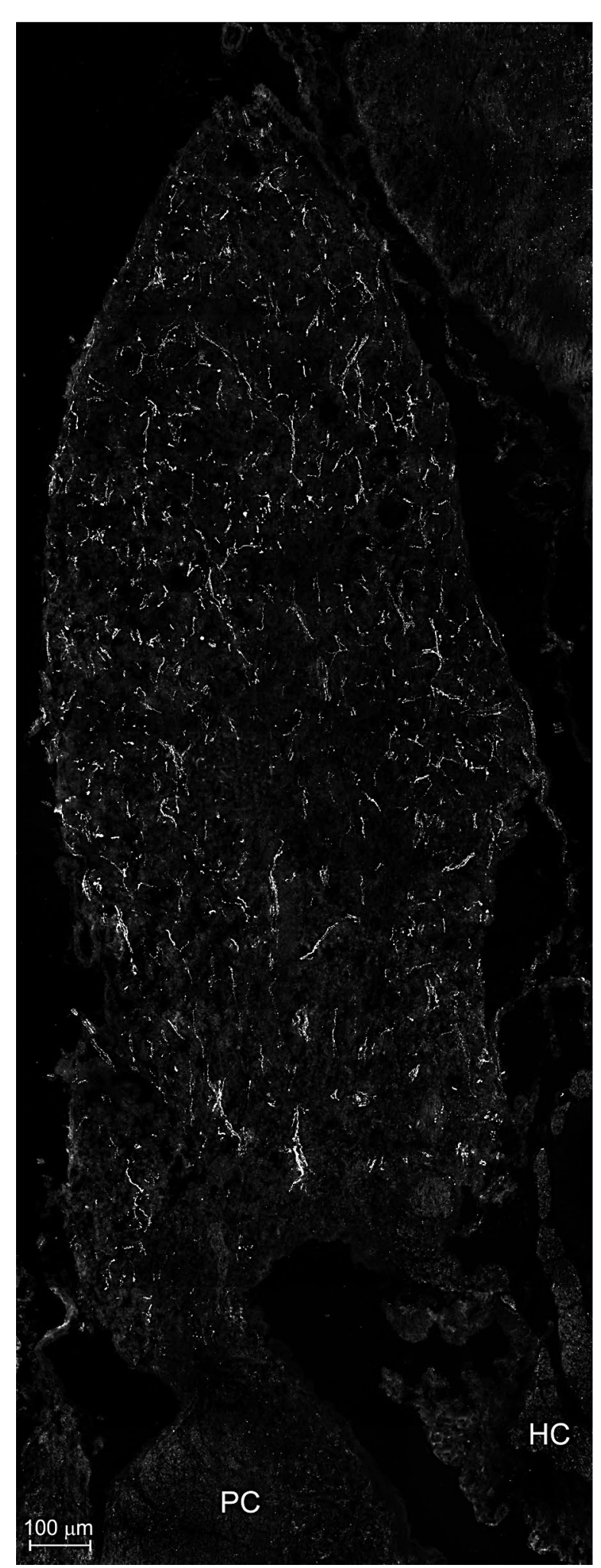

Figure 2. Distribution of substance P-immmunoreactive (SP-IR) in the fox pineal gland; $\mathrm{PC}$ - the posterior commissure; $\mathrm{HC}$ - the habenular commissure.
SP-positive nerve fibres. Namely, the SP-IR fibres were slightly more numerous in the distal and middle parts of the fox pineal gland than in the proximal one. The prominent regional differences in the density of SP nerve fibres have been described in rodents [13]. In the rat and the cotton rat, SP nerve fibres were mainly located in the superficial pineal gland and in the pineal stalk, while only single nerve terminals were found in the deep pineal gland [13]. Similarly, the nerve fibres were present almost exclusively in the superficial part of the pineal gland in the hamster [11]. In contrast, the uniform distribution of SP-positive fibres was reported in the bovine [13], pig $[25,29]$ and macaque [33].

The interspecies differences in distribution of SP-positive fibres are probably related to variable sources of these fibres. In rodents, the vast majority of SP-IR fibres comes from the peripheral ganglia and enters into the pineal gland via the nervi conarii [13]. The use of combined technique of neuronal tracing and immunohistochemistry revealed that SP-IR fibres in the rat pineal gland originate, at least in part, from the trigeminal ganglion [32]. SP-IR fibres remained unchanged following bilateral removal of the superior cervical ganglia in the rat pineal gland [42]. In contrast, the superior cervical ganglionectomy performed in the cotton rat resulted in considerable decrease in the number of intrapineal SP-positive nerve fibres [13]. It is worth to note that this procedure completely eliminated the fibres immunopositive to tyrosine hydroxylase and neuropeptide $Y$, but no SP-IR fibres from the nervi conarii. Thus, it could be concluded that both sympathetic and non-sympathetic nerve fibres form the nervi conarii and enter into the pineal gland via this route [13]. The sparse fibres present in the deep pineal gland of rodents may have their source in the central nervous system. In the rat pineal gland, it was demonstrated that SP-positive cells located in the medial habenular nucleus give their processes to the deep pineal gland [13]. In turn, the results obtained in the bovine suggest mainly the central origin of SP-IR fibres [18]. In this species numerous SP-IR cells occur in the habenular nucleus, from where the positive fibres penetrate towards the pineal gland. The positive fibres are also present in the posterior commissure. Similarly, in the pig, numerous SP-IR nerve penetrate from the habenular and posterior commissures to the 

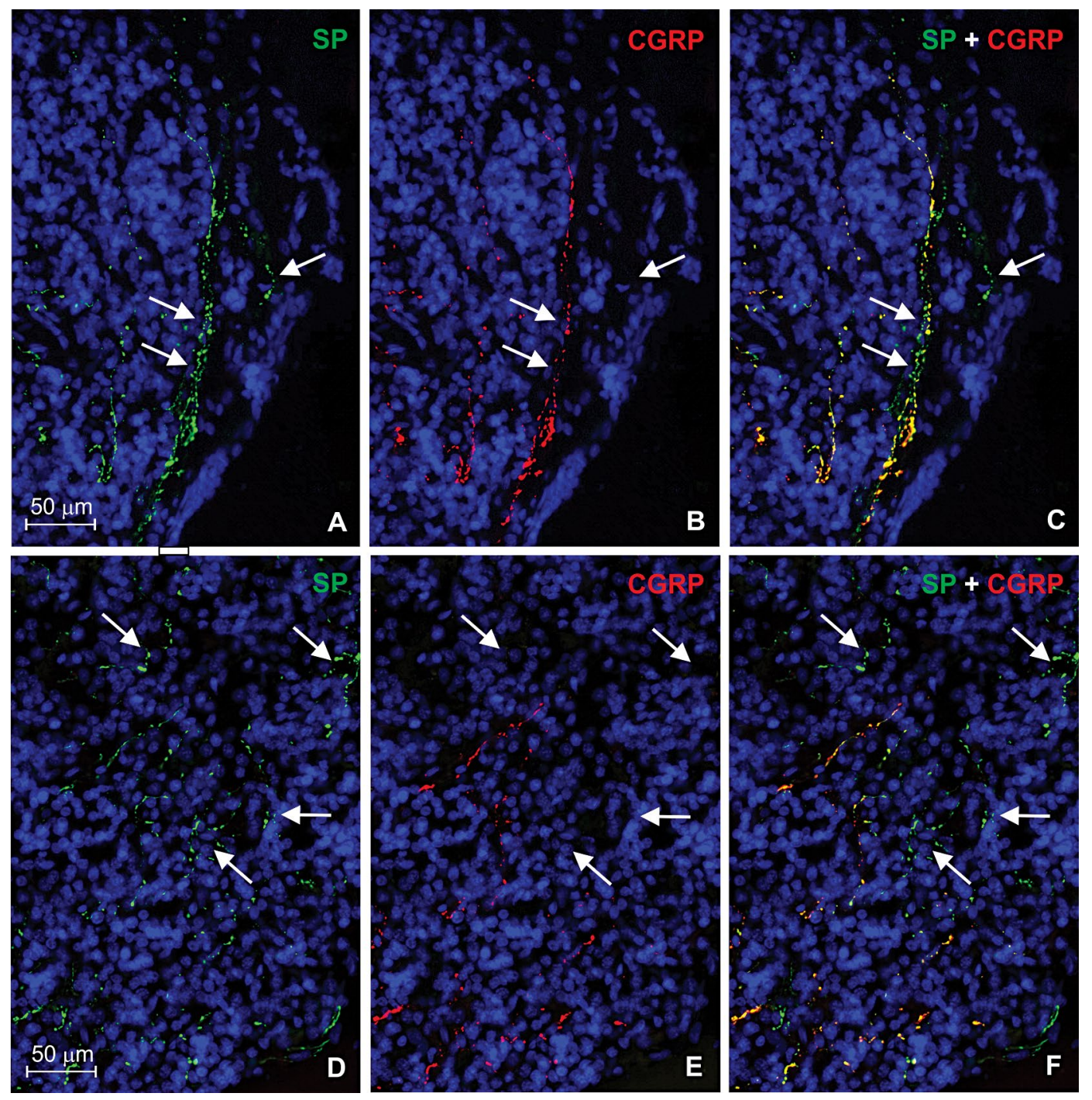

Figure 3. Double immunostaining with antibodies against substance $P(S P)$ and calcitonin gene-related peptide (CGRP); A, B, C. Bundles of nerve fibres in the capsule and in the peripheral part of parenchyma; D, E, F. Network of nerve fibres in the parenchyma. Note that the vast majority of SP-positive fibres are also CGRP-positive. Some fibres show positive reaction to SP and negative to CGRP (arrows).

pineal gland, and form thick bundles in the proximal part of the gland [28]. Double immunocytochemistry with antibodies against SP and CGRP demonstrated two populations of SP-IR fibres in the pig pineal gland [11]: (1) SP-positive/CGRP-negative fibres present in the proximal part of the organ and the commissural areas, originating, at last in part, from the neurons located in the habenular nucleus, (2) SP-positive/ CGRP-positive fibres present in the distal and middle parts of the organ, having probably a peripheral origin. The intrapineal neuronal-like cells should be considered as an another source of SP-IP fibres. Such cells have been found in the cotton rat and the human; however, they are rather sparse $[13,27]$.
In our study, the careful examination of serial sections demonstrated that the SP-IR fibres penetrate inside the gland parenchyma through the pineal capsule as the nervi conarii. Furthermore taking into consideration the intrapineal distribution of fibres we can deduce the SP-positive innervation of the fox pineal gland has a peripheral origin. This assumption is strongly confirmed by the absence of SP-IR cells and fibres in the posterior and habenular commissural areas adjoining to the pineal gland well as the lack of SP-IP cell bodies inside the gland.

Another peptide examined in our study was CGRP. The CGRP-IR fibres were less abundant that SP-IR fibres in the fox pineal gland, however the distribution 
pattern of CGRP was essentially the same as that of SP. Like, SP-IP fibres, CGRP-IR fibres were slightly more numerous in the distal and middle parts of the gland than in the proximal one. The habenular and commissural areas were devoid of any CGRP positive elements.

The double immunofluorescence staining has revealed that all fibres containing CGRP are also SP positive; however, there are some nerve fibres with the positive reaction for SP and negative for CGRP. Our results demonstrate the presence of two populations of SP-IR nerve fibres in the fox pineal gland: these simultaneously expressing CGRP and those without CGRP. Both populations enter the pineal gland via the nervi conarii.

The distribution patterns of CGRP-IR nerve fibres are similar in the pineal glands of all studied species up till now. In rodents, the density of CGRP-positive fibres is moderate in the superficial pineal gland and the stalk while in the deep pineal only single fibres are presented [17]. The fibres are absent in the habenular and posterior commissures. In the pig, the nerve fibres containing CGRP occur exclusively in the distal and middle parts of the pineal gland.

The question arises, what are the physiological roles of SP and CGPR in the pineal gland? Until recent$l y$, it has been considered that SP has no influence on the pineal secretory activity. The research performed on the rat pinealocytes demonstrated that the application of SP did not influence the CAMP formation as well as the basal or norepinephrine-stimulated serotonin $\mathrm{N}$-acetyltransferase activity and melatonin secretion [38]. Similar data have been obtained for melatonin secretion from bovine pinealocytes [36]. The recent studies performed on the rat pineal organ cultures, shed new light for the role SP [22]. At the presynaptic site, SP potentiates the release of norepinephrine from the sympathetic preganglionic fibres endings. This effect is mediated through neurokinin 1 receptor. Activation of this receptor by SP augments the intracellular $\mathrm{Ca}^{2+}$ concentration what stimulates the release of norepinephrine. At the postsynaptic site, SP inhibits the norepinephrine-inducted increase $\mathrm{N}$-acetyltransferase activity and melatonin synthesis [22]. These data clearly demonstrate that SP plays a modulatory role in the adrenergic regulation of melatonin synthesis, acting both at the presynaptic and postsynaptic levels. The role of CGRP in the pineal gland has been not investigated. This peptide may participate in the control of blood flow.

\section{CONCLUSIONS}

Taking all these together, it is reasonable to conclude that the fox pineal gland is richly supplied by SP- and CGRP-positive nerve fibres. The fibres enter into the pineal gland via the nervi conarii and create numerous bundles in the capsule, from where they penetrate to the connective tissue septa and later to the parenchyma. There are two population of SP-positive fibres, differing by the presence or lack of CGRP. The obtained results seem to be interesting because SP/CGRP innervation of the fox pineal gland, especially their density and origin, differs from hitherto examined mammals. In our opinion, the presence of nerve structures immunoreactive to SP and CGRP indicates participation of these peptides in the regulation of synthesis and secretion of melatonin. Further research, taking into account the presence of receptors of SP and CGRP as well as effects of the peptides on melatonin secretion in vitro, are necessary to fully understand the role of SP and CGRP in the pineal physiology in carnivores.

\section{Founding}

Project financially supported by Minister of Science and Higher Education in the range of the program entitled "Regional Initiative of Excellence" for the years 2019-2022, Project No. 010/RID/2018/19, amount of funding 12,000,000 PLN.

\section{REFERENCES}

1. Boya J, Calvo JL, Rancaño D. Structure of the pineal gland in the adult cat. J Pineal Res. 1995; 18(2): 112-118, indexed in Pubmed: 7629690.

2. Bulc M, Nidzgorska A, Całka J. Immunohistochemical characterization of the porcine nodose ganglion. Acta Histochem. 2013; 115(5): 440-446, doi: 10.1016/j.acthis.2012.10.007, indexed in Pubmed: 23206556

3. Bulc M, Lewczuk B, Prusik M, et al. Calcium concrements in the pineal gland of the Arctic fox (Vulpes lagopus) and their relationship to pinealocytes, glial cells and type I and III collagen fibers. Pol J Vet Sci. 2010; 13(2): 269-278, indexed in Pubmed: 20731181.

4. Calvo J, Boya J, Garcia-Mauriño JE, et al. Ultrastructure of the pineal gland in the adult dog. J Pineal Res. 1988; 5(5): 479-487, indexed in Pubmed: 3171892.

5. Chen $\sqcup$, Zhang FG, Li J, et al. Expression of calcitonin gene-related peptide in anterior and posterior horns of the spinal cord after brachial plexus injury J Clin Neurosci. 2010 17(1): 87-91 doi: 10.1016/j.jocn.2009.03.042, indexed in Pubmed: 19969463.

6. Datar P, Srivastava S, Coutinho E, et al. Substance P: structure, function, and therapeutics. Curr Top Med Chem. 2004; 4(1): 75-103, indexed in Pubmed: 14754378.

7. De Felipe C, Herrero JF, O'Brien JA, et al. Altered nociception, analgesia and aggression in mice lacking the receptor for substance $P$. Nature. 1998; 392(6674): 394-397, doi: 10.1038/32904, indexed in Pubmed: 9537323.

8. Gerard NP, Garraway LA, Eddy RL, et al. Human substance P receptor (NK-1): organization of the gene, chromosome localization, and functional expression of cDNA clones. Biochemistry. 1991; 30(44): 10640-10646, doi: 10.1021/bi00108a006, indexed in Pubmed: 1657150.

9. Goto K, Miyauchi T, Homma S, et al. Calcitonin gene-related peptide in the regulation of cardiac function. Ann N Y Acad Sci. 
1992; 657: 194-203, doi: 10.1111/j.1749-6632.1992.tb22768.x, indexed in Pubmed: 1637085.

10. Kado M, Yoshida A, Hira Y, et al. Light and electron microscopic immunocytochemical study on the innervation of the pineal gland of the tree shrew (Tupaia glis), with special reference to peptidergic synaptic junctions with pinealocytes. Brain Res. 1999; 842(2): 359-375, doi: 10.1016/s0006-8993(99)01856-9, indexed in Pubmed: 10526132.

11. Leander P, Vrang N, Møller M. Neuronal projections from the mesencephalic raphe nuclear complex to the suprachiasmatic nucleus and the deep pineal gland of the golden hamster (Mesocricetus auratus). J Comp Neurol. 1998; 399(1): 73-93, indexed in Pubmed: 9725702.

12. Matsushima S, Sakai Y, Hira Y, et al. Immunohistochemical studies on sympathetic and non-sympathetic nerve fibers and neuronal cell bodies in the pineal gland of cotton rats, Sigmodon hispidus. Arch Histol Cytol. 1994; 57(1): 47-58, indexed in Pubmed: 7515253.

13. Matsushima S, Sakai Y, Hira Y. Peptidergic peripheral nervous systems in the mammalian pineal gland. Microsc Res Tech. 1999; 46(4-5): 265-280, doi: $10.1002 /(\mathrm{SICI}) 1097-$ 0029(19990815/01)46:4/5<265::AID-JEMT4>3.0.CO;2-S, indexed in Pubmed: 10469463.

14. Matsuura T, Sano Y. distribution of monoamine-containing nerve fibers in the pineal organ of untreated and sympathectomized dogs. Fluorescence- and immunohistochemical studies. Cell Tissue Res. 1983; 234(3): 519-531, doi: 10.1007/bf00218648, indexed in Pubmed: 6362886.

15. Matsuura $T$, Kawata $M$, Yamada $H$ et al Immunohistochemical studies on the peptidergic nerve fibers in the pineal organ of the dog. Arch Histol Jpn. 1983; 46(3): 373-379, indexed in Pubmed: 6357138.

16. Mondain-Monval M, Smith AJ, Simon P, et al. Effect of melatonin implantation on the seasonal variation of FSH secretion in the male blue fox (Alopex lagopus). J Reprod Fertil. 1988; 83(1): 345-354, doi: 10.1530/jrf.0.0830345, indexed in Pubmed: 3135390.

17. Møller M. Introduction to mammalian pineal innervation. Microsc Res Tech. 1999; 46(4-5): 235-238, doi: 10.1002/(SICI)10970029(19990815/01)46:4/5<235::AID-JEMT1>3.0.CO;2-9, indexed in Pubmed: 10469460.

18. Møller $M$, Phansuwan-Pujito $P$, Govitrapong $P$, et al. Indications for a central innervation of the bovine pineal gland with substance P-immunoreactive nerve fibers. Brain Res. 1993; 611(2): 347-351, doi: 10.1016/0006-8993(93)90525-r, indexed in Pubmed: 7687507.

19. Møller M, Phansuwan-Pujito P, Pramaulkijja S, et al. Innervation of the cat pineal gland by neuropeptide $Y$-immunoreactive nerve fibers: an experimental immunohistochemical study. Cell Tissue Res. 1994; 276(3): 545-550, doi: 10.1007/bf00343951, indexed in Pubmed: 8062343

20. Møller M, Ravault JP, Cozzi B. The chemical neuroanatomy of the mammalian pineal gland: neuropeptides. Neurochem Int. 1996; 28(1): 23-33, indexed in Pubmed: 8746761.

21. Møller M, Baeres FMM. The anatomy and innervation of the mammalian pineal gland. Cell Tissue Res. 2002; 309(1): 139-150, doi: 10.1007/s00441-002-0580-5, indexed in Pubmed: 12111544

22. Mukda S, Møller M, Ebadi $M$, et al. The modulatory effect of substance $P$ on rat pineal norepinephrine release and melatonin secretion. Neurosci Lett. 2009; 461(3): 258-261, doi: 10.1016/j. neulet.2009.06.040, indexed in Pubmed: 19545608.

23. Nieminen P, Pyykönen T, Asikainen J, et al. Effects of fasting and exogenous melatonin on annual rhythms in the blue fox (Alopex lagopus). Comp Biochem Physiol A Mol Integr Physiol. 2004; 139(2): 183-197, doi: 10.1016/j.cbpb.2004.09.002, indexed in Pubmed: 15528167.

24. Nowicki M, Lewczuk B, Kosacka J, et al. Pituitary adenylate cyclase-activating polypeptide-immunoreactive (PACAP-IR) nerve fibers in the pig pineal gland. Folia Histochem Cytobiol. 2002; 40(2): 149-150, indexed in Pubmed: 12056619.

25. Nowicki M, Wojtkiewicz J, Lewczuk B, et al. Peptidergic and nitrergic innervation of the pineal gland in the domestic pig: an immunohistochemical study. Anat Histol Embryol. 2007; 36(4): 311-320, doi: 10.1111/j.1439-0264.2007.00767.x, indexed in Pubmed: 17617110.

26. Park SW, Yan YP, Satriotomo I, et al. Substance P is a promoter of adult neural progenitor cell proliferation under normal and ischem- ic conditions. J Neurosurg. 2007; 107(3): 593-599, doi: 10.3171/ JNS-07/09/0593, indexed in Pubmed: 17886560.

27. Phansuwan-Pujito $P$ Govitrapong $P$ Møller $M$ Immunohistochemical demonstration of opioids and tachykinins in human pineal gland. J Med Assoc Thai. 2005; 88 Suppl 1: S56-S65, indexed in Pubmed: 16858936

28. Przybylska-Gornowicz B, Helboe L, Lewczuk B, et al. Somatostatin and somatostatin receptors in the pig pineal gland during postnatal development: an immunocytochemical study. Anat Rec. 2000; 259(2): 141-149, doi: 10.1002/(SICI)10970185(20000601)259:2<141::AID-AR4>3.0.CO;2-F, indexed in Pubmed: 10820316

29. Przybylska-Gornowicz B, Lewczuk B, Møller M. Immunohistochemical localization of substance $P$ in the pineal gland of the domestic pig. Folia Histochem Cytobiol. 2000; 38(2): 85-90, indexed in Pubmed: 10833673.

30. Przybylska-Gornowicz B, Lewczuk B, Møller M. Vasopressinergic innervation of the pig pineal gland. Folia Histochem Cytobiol. 2002; 40(1): 3-8, indexed in Pubmed: 11885805.

31. Reuss $S$. Trigeminal innervation of the mammalian pineal gland. Microsc Res Tech. 1999; 46(4-5): 305-309, doi: 10.1002/(SICI)10970029(19990815/01)46:4/5<305::AID-JEMT7>3.0.CO;2-\#, indexed in Pubmed: 10469466

32. Reuss S, Riemann R, Vollrath L. Substance P- and calcitonin gene-related peptide-like immunoreactive neurons in the rat trigeminal ganglion--with special reference to meningeal and pineal innervation. Acta Histochem. 1992; 92(1): 104-109, doi: 10.1016/ S0065-1281(11)80146-7, indexed in Pubmed: 1374581.

33. Ronnekleiv OK. Distribution in the macaque pineal of nerve fibers containing immunoreactive substance $\mathrm{P}$, vasopressin, oxytocin, and neurophysins. J Pineal Res. 1988; 5(3): 259-271, indexed in Pubmed: 2457073.

34. Rose J, Oldfield J, Stormshak F. Apparent role of melatonin and prolactin in initiating winter fur growth in mink. Gen Comp Endocrinol. 1987; 65(2): 212-215, doi: 10.1016/0016-6480(87)90168-7, indexed in Pubmed: 3817444

35. Rosenfeld MG, Mermod JJ, Amara SG, et al. Production of a novel neuropeptide encoded by the calcitonin gene via tissue-specific RNA processing. Nature. 1983; 304(5922): 129-135, doi: 10.1038/304129a0, indexed in Pubmed: 6346105.

36. Schomerus $C$, Laedtke $E$, Olcese J, et al. Signal transduction and regulation of melatonin synthesis in bovine pinealocytes: impact of adrenergic, peptidergic and cholinergic stimuli. Cell Tissue Res. 2002; 309(3): 417-428, doi: 10.1007/s00441-002-0588-x, indexed in Pubmed: 12195298

37. Shiotani Y, Yamano M, Shiosaka S, et al. Distribution and origins of substance $P(S P)$ - calcitonin gene-related peptide (CGRP)-, vasoactive intestinal polypeptide (VIP)- and neuropeptide Y (NPY)-containing nerve fibers in the pineal gland of gerbils. Neurosci Lett. 1986; 70(2): 187-192, doi: 10.1016/0304-3940(86)90461-1, indexed in Pubmed: 2430238.

38. Simonneaux V, Ribelayga C. Generation of the melatonin endocrine message in mammals: a review of the complex regulation of melatonin synthesis by norepinephrine, peptides, and other pineal transmitters. Pharmacol Rev. 2003; 55(2): 325-395, doi: 10.1124/ pr.55.2.2, indexed in Pubmed: 12773631.

39. Smith AJ, Mondain-Monval M, Andersen Berg K, et al. Effects of melatonin implantation on spermatogenesis, the moulting cycle and plasma concentrations of melatonin, $\mathrm{LH}$, prolactin and testosterone in the male blue fox (Alopex lagopus). J Reprod Fertil. 1987; 79(2): 379-390, doi: 10.1530/jrf.0.0790379, indexed in Pubmed: 3572874.

40. Teclemariam-Mesbah R, Ter Horst GJ, Postema F, et al. Anatomical demonstration of the suprachiasmatic nucleus-pineal pathway. J Comp Neurol. 1999; 406(2): 171-182, indexed in Pubmed: 10096604

41. Vigh B, Vigh-Teichmann I. Two components of the pineal organ in the mink (Mustela vison): their structural similarity to submammalian pineal complexes and calcification. Arch Histol Cytol. 1992; 55(5): 477-489, indexed in Pubmed: 1295547.

42. Zhang ET, Mikkelsen JD, Møller M. Tyrosine hydroxylase- and neuropeptide $Y$-immunoreactive nerve fibers in the pineal complex of untreated rats and rats following removal of the superior cervical ganglia. Cell Tissue Res. 1991; 265(1): 63-71, doi: 10.1007/ bf00318140, indexed in Pubmed: 1680561. 